UDC 811.111

DOI: $10.17223 / 24109266 / 8 / 7$

\title{
MEDIA TEXTS: MAIN STRUCTURES AND VALUES FROM THE PERSPECTIVES OF INTERCULTURAL COMMUNICATION
}

\author{
A.G. Pastukhov \\ Orel State Institute of Culture (Orel, Russian Federation) \\ E-mail: alexander.pastukhov@yandex.ru
}

\begin{abstract}
The aim of the paper is to indicate main techniques of modeling the media text structure for the purpose of finding practical solutions for their description and to identify essential characteristics i.e. functional and stylistic features of the media genres etc. The paper deals with a wide range of media text issues as a cultural object where current views on its nature and criteria for an adequate understanding are given. The problem of "Other" and "Foreign" in the reflection of modern media by all evidence is one of the most difficult to comprehend. The article is devoted to the modern manifestations of national-specific information encoded within the media text. The paper also focuses on the problems of the cultural transfer as a key question that manifests the values of media texts which can be reconstructed through the transcultural analyses. The forms of cultural specifics are analyzed, whereas the concept of cultural intertextuality is introduced and discussed as an important fact for pragmatic and cultural text retrieval. The defined forms of cultural specifics are illustrated by several examples taken from media texts that may have practical and didactical implications. Based on comparative analysis the study of cultural connotations reflects current opportunities and solutions for intercultural information policy and especially for emotional impact on the audience in a multicultural and globalizing world.
\end{abstract}

Keywords: media text; media culture; media impacts; media communication; multiculturalism; intercultural code; intercultural competence; culture tag.

\section{Introduction}

Modern processes of social interaction are determined by parameters of interpersonal communication. Structural changes and relationships between individuals and their communicative culture are increasingly associated with achievement of information technologies and introduction of new forms of social and personal interaction. The world-picture knowledge has developed as a move to the consequent formation of aesthetic ideas, ethics rules and morality. Significant are the social practice and personal experience, as well as the study of the stereotypes of communicative behavior.

Finally, the parameters of modern media culture are focused on the most important linguo-cultural stereotypes that appear as a result of the ethno-centric reaction - specific response that reflects the experience of "native" and "foreign" culture. So the mechanisms and self-generation of ethnic and 
cultural stereotypes are closely connected with today's realities. Recognition and overcoming of ethnic and cultural conflicts can revealingly characterize the modern dialogue between peoples and cultures.

Important options for any language culture may provide its cognitive basis that includes the deepest comprehension of the communication culture. It consists of values and attitudes that are mainly crystallized by current cross-cultural stereotypes. The idea of a foreign culture is based on the obvious and false stereotypes that typically influence the world picture and foreign cultures too. At the same time, the most important view can actually manifest the existence of the individual as a bicultural or polycultural language person itself, while learning languages and cultures.

\section{Intercultural Communication}

The flow of the communicative processes is normally characterized by the complex of factors that reflect ultimate realization of interaction between different cultures. Considering the bunch "Language - Text - Culture", the following framework appears as a comprehensive feature of the text that occurs in the translation of cultures themselves in all manifestations and individual interactions [1:35].

It is no coincidence that the study of stereotypes is the priority over consideration of the stereotypes. In a foreign culture, demonstration of the communicative situations in native and foreign language determines a special cultural space. It is understood as an extension of the world view and is associated with continuous development. The special dynamics of representation in a culture may give rise to an expanded definition of the native language in today's globalizing world.

The nature of intercultural relations evidences this actual social phenomenon in its common practice and relation to the world's cultures. This phenomenon is also associated with the social macro- and micro-levels which are conclusively seen as a response to attempts at constructing communicative situations in their aim to minimize the speech that also give a prompt access to communication and its effectiveness. Intercultural communication can assume therefore the equality of people (this imaginary world is not always equal either to their own or another culture) and predestinate numerous forms of reflection, self-reflection, mutual clarification, dialogue etc. Similarly, this communication is seeking for similarities and differences, because they provide not only regulators of other cultures, but also have their directing, distinguishing and participating role in the architecture of the inner world that is determined by "my" world view contrasted with others'. The relevant point of view is an individual construction, because accentuation on differences complicates and hinders dialogue. 
Related issues of Intercultural Competence (IC) are logically combined by a framework that contains linguistic and nonlinguistic factors. Endowed with linguistic and non-linguistic projections, IC is well integrated into "Other" and "Foreign" cultures. Therefore, while studying texts in the divergent social contexts, it is important to understand that discourses can make it easier to declare and recover a common message (text). From the current context its interpretation can be obtained, but it is more difficult to explicate it from simple understanding. Thus, intercultural competence means an essential orientation in contexts and discourses of other cultures [2: 33]. Intercultural competence in the contrary must have the mastering skill by setting the text into historical context or through the possibility of adapting formulas and models of media texts. The understanding and proper comeasurement with positions of the recipient within the current context bring them into historical dynamic development and processes of divergent human behavior.

In order to fulfill the social role of intercultural communication (IC) the above task becomes more interdisciplinary. This approach joins with a whole network of various aspects of sociological, philological, theological, pedagogical, philosophical, historical, linguistic knowledge due to their understanding as a compensatory response for needs of specialization. They require at the same time a rapid deepening of consciousness and far-ranging relationships within this intercultural paradigm.

Media Culture. Illustrative indicators of sustainable linguistic reflections are observed in the area of "cultural values" translation, which is called media culture. Media culture as a special sphere of speech existence is of great interest to researchers. It is also closely related to the promotion of new technologies and strict definitions of the borders and modern information policy in the communicative space. While using media texts (press, radio, $\mathrm{TV}$, Internet etc.), certain speech units are essentially embedded into the programs and texture of contemporary media speech that directly or indirectly affect media culture in general. According to N. Kirillova, "media culture in its totality of information and communication instruments, material and intellectual values is produced by the cultural-historical development, forms of public awareness and socialization of the individual" [3: 31].

In earlier studies $[4,5]$ we have showed the importance of studying the various aspects of cultural objects that are significantly marked by the multicultural environment. They objectively reveal the cultural differences: regarding a wide array of media texts, we would like to focus attention on the effects of the similar Russian concept «интеркультура» in its relation to the conditions of the globalized world and related concepts of 'transculture' and 'multiculturalism'.

According to the approaches of most Russian researchers, interculture means mutual relations between people from different cultures. Concerning 
multifaceted relations and diverse nature they outline the remits of the field of contemporary reality - interculture - as a collective concept in theory and practice that is also typical for methods and arrangements in a society covering a wide historical and contemporary background of various cultural spaces, individuals and groups. In this so-called "first line of public importance", adjustment for trans-, multi- and intercultural aspects are revealed in its significant differences among them.

Multicultural approach, which is rather problematic in its nature, produces the common compromise between cultures. Culture can also exist without it. In this case, people feel a specific immutable identity. But it does not occur, when the leading idea of culture and cultural development is based on the relationships of images and clichés, beyond the uniqueness and uniformity. If we mean a homogeneous society, it can heavily recover moderated trans-cultural differences that are not always related to crossing the boundary in the relationship between individuals. It is absolutely exhausted, because this area appears as a field of trans-cultural, inter-cultural or interreligious contacts.

In the evaluation of a variety of contexts and situations of extreme actuality or, better to say, conversely, moderated forms of relationships are incalculable. After all, individuals are understood not as cultural mestizos. It is not enough to fix the local and aboriginal differences. The translation of multicultural factors (interculture) is regulated by trans-cultural laws and behavior. It considers also the behavior of foreign migrants that came to Russia in the early 1990s etc. Do they have retained native religion, traditions, language and culture? The answer to the question gives an opportunity to understand conditions under which society is slowly transformed into multi- and intercultural. This is due largely to behaviors that did not previously exist, but are in the process of formation, suitable to new conditions and challenges of the social environment. So the key concept of human life CULTURE - implies furthering the logical understanding of basic problems of communication in general. According to individual decision, the whole complex of problems is associated with the ability to create and recognize text, language etc. Analyzing and understanding patterns of behavior lead to not only the efforts of the rational, but also to emotional communication development.

Intercultural understanding and mutual penetration are widely correlated with a special kind of hermeneutic interaction, with the category of "Other" [6]. It is constructed as a perception of the facts in which design of values vary and operational and symbolic systems are implemented. The concepts of intercultural understanding and intercultural hermeneutics per se can be used interchangeably, since they include similar behavior rules, translations and text interpretations. But only perception of artifacts can define the cultural contexts and subsequent connections between "Other" and "Foreign". 
It is no coincidence therefore that an empirical analysis of the cultural phenomenon of communication and media captures the widest scope of literary questions, sociology, psychology, semiotics etc. that previously were quite relevant to the designated spheres: journalistic, text-linguistic, discursive, analytical etc. In the 'cultural' texts, however, it is very important to complement these approaches by meaningful analysis of numerous stereotypes for their implicit cultural content, as well as to clarify the question of whether "cultural" category or the rules of public opinion affect [5].

Emphasizing the language sign as a cultural icon we mean not only the hidden significance and cultural content that may have characteristic vectors and cultural dimensions. Linguistic symbols hereby function as a tag, an orientation or a code of culture.

Culture Tags are linguistic symbols that directly point to the ethnography of a language community, allowing to recognize one culture and to distinguish it from another in accordance with simple features. Culture orientations include linguistic symbols, orienting in the cultural signs that indicate the direction to recognize cultures that differ one from another or from the observed phenomena. Culture Codes are language symbols that require complex description based on a comprehensive interpretation that allows identifying the culture in all vectors and measurements. The difference between language symbols between cultures depends not only on the depth of information, but also on the communication speed. The culture tags are equivalents for "quick postings". Some culture orientations in the contrary can appear as a symbol for "slow messages". Codes of culture are also symbols for "slow messages" [7: 44].

So media culture covers a wide complex of factors that is constantly updated by framework of symbolic media forms reflecting the global world picture. Analyzing the media culture and especially its intercultural aspect, we have to highlight the characteristics that are inherent in it and typical for the information society (spontaneity, lightness, acceptance of norms and stereotypes, promotion of tolerance, manifestations of individuality, mobility values etc.). In any case, the comprehension of "Foreign" and "Other" cultures cannot be left without attention. Moreover, it is very significant for the media extension process and its positive or negative ethno-cultural connotations.

Media Text. The study of texts in the traditional media research is an important factor from the point of view of development and public communication analyses. The main feature of the media text is its "public context, which is due to the nature of the communication of various social groups in the objective and subjective conditions of their interaction. The formation of a typology and establishing forms, communication standard formats, clarification of the principles and methods of media text construction include therefore strict requirements concerning certain text types. The media text typology is grounded on a functional and stylistic basis that allows consider- 
ation of the specifics of actual linguistic text features and their correlations among the media sphere, that also have some pragmatic attitudes" [8: 82].

In the conditions of meaningful communication the media attitudes discover vast empirical material. It is closely related to the analysis aims that are relevant for description of media texts, reflecting a wide range of patterns and immanent messages. The media discourse can reflect further the recent conceptualizations in form of specific media research that becomes a source of examples illustrating features and phenomena, for example, political or organizational discourse, where processes of categorization, conceptualization of information and their reception are given. Obviously the results of our research concerning media text and/or media discourse as a basis for determining characteristics of media text becomes a significant bonus that is obtained in addition to the main results.

The public media sphere is a special field of activity that is rich and meaningful to society, and its language means may differ from the language that is used in other fields. With this usage the field of media (or public media) is of concern to media linguistics - a special branch of linguistics that deals with the relationship between language and media [9: 30].

From this perspective, linguistics is searching now for recurring communicative purposes of texts. Moreover, media provides strategies for practice with their logical patterns to save processing expenses and at the same time to produce continuously attractive "news". Among other things, the text linguistics examines such factors which make a text-to-text and patterns for language use in the "quick", industrial journalistic media [Ibid.: 183-184].

Taking into consideration the media text problems, it is necessary to determine gradually the observation of the empirical world focusing on specific aspects of the theoretical and empirical material description, as well as consistently proving theoretical foundation approach to its illustrations. The perspective studies, as well as realization of the advantages and disadvantages of techniques and methods used in the analysis of media text can significantly increase the explanatory intensity of them.

Thus formulated universal relevance [10: 196-197], specific patterns of media text [9: 197-198], as well as linguo-cultural significance, relation to the social context and their syntagmatic receive particular interest, where types of media text are characterized by different ratios of event; i.e. actional, axiological and thematic components are associated respectively with specific weight of expressive language means $<\ldots>$. In the space of a media text there is enclosed information on the dominant relevant linguistic culture; its value orientations and matching cause the reception of media texts and their meaningful interpretation [10: 198; 11: 15-17].

Importance of media studies can be proved by the media literacy, which not only captures the process of understanding and using media in its active form, but also involves a conscious and critical understanding of the 
media nature, as well as of the methods and techniques that are used in persuasive communication [12]. It can also expect a cultural information, which inherently carries positive reflection of ethnic diversity causing by interests to the life and experience of people.

From the standpoint of the communicant media, in combination with the creolized media, texts are not fundamentally different from the homogeneous verbal text. Such texts are determined by categories of textual integrity and connectivity. The integrity is understood as a unity of the text, ability to exist in communication on the basis of the internally and externally organized whole. Connectivity reflects substantial and formal communication of the text. Both categories are closely interrelated and integrated into creolized communicative and cognitive imaginations of sender that individually perform the 'face' of the author or his 'collaborators' (artist, photographer, editor, etc.). A common topic disclosed by verbal, iconic and other paralinguistic means in media text appears as a complicated textual form with verbal and/or iconic elements of visual, structural, semantic and functional nature aimed at the comprehensive pragmatic effect on the recipient [13: 17].

Media Text Typologies. The problem of text typology is extremely relevant, because only through text activity can the effectiveness of the text initiations be fixed. The information act in the modern culture makes the text one of the channels of mass communication. More recently, media practice faced some extreme difficulties, or even impossibility of positioning the individual facts and phenomena through the media text. But now the situation has changed: new forms of media give a clear impetus to the media text and media text system combinations. Linguists are increasingly talking on the emergence of new text types that primarily reflect their production environment. It should be noted that the texts of new media, i.e., media texts are created or transmitted by new communication channels that cannot always support their linguistic or extra-linguistic characteristics.

Since the beginning of text linguistics in the 1960s and text typology discussion, the essential elements of this sub-discipline are not considered by linguistics [14: 62]. Early concepts of linguistic pragmatics were integrated into text theory; texts therefore act in the context of performance communication and society. However, there remains the question what the yielding text typology is and what significance it has. The text typology issues determine special ways to controversial site rules, because of their fundamental importance and position at the intersection of scientific disciplines [15: 12]. This disagreement relates initially nothing less than the very basic methodological question: what are the text types and how can they be designed. At the center of linguistic typological approach remains an attempt to overcome the supposed (!) arbitrariness and inconsistency of everyday text examples and an objective overview that can win the universe of texts [16: 153]. 
In this case the status quo of the tradition in the text type research is based on the essential characteristics and classifications of texts, but a new classification system is formed that encompasses various typologies due to the complexity of the subject matter. In our opinion, the text typology is ideally characterized by:

- Exhaustiveness: all typological elements are recognized;

- Homogeneity: typology includes a uniform criterion;

- Monotype: elements that are typologized, uniquely assigned to the types;

- Finiteness: number of text types is limited.

In more inductive approaches the selection criteria of empirical texts and eventual classifications are deductively formed. The applied character of empirical studies is often less motivated by practical questions than through purely scientific research; it directs and clarifies needs of a valid basis derived from text rules for all texts, or for certain types of text, just intuitively differentiated. The studied text types or genres can be distinguished also by systematic application of linguistic criteria. In our attempt to describe the world of texts by objective science, however, one problem should be kept in mind. We mean therefore concepts and categories that are not simply presented, but always based on methodically reflected and formed perceptions and interpretations [17].

This is just only one of the typological proposals in all variety of reflections of the "arbitrariness" and "inconsistency" of everyday texts. It is probably less overcome than increased. One typical example of this types is considered in the general function of text that should classify in abstract models of language the variety of those linguistic phenomena which relate to the mentioned issues. The language of media will undergo even a single structure or act that is needed. Probably they contain intra-professional knowledge domains where situation and text types differ.

\section{Conclusion}

The ideas of humanism and tolerance towards the conditions of modern life span individuals and ethnic groups, their knowledge and ethnic existence, consolidation and integration, preservation and development of their cultural identity, reflection or conflict of ethno-reconciled media activity. Remembering that trans-culture is one of the most developed social means the transition from the sphere of the material into the spiritual sphere, in the field of mass psychology and social interactions rise to a considerable extent and feed stereotypes. In its basic intention axiological stereotypes a priori include the personal experience, regularity, stability, etc. and generate a number of consequences among which may be mentioned a potential of subjectivity, appraisal, expression (axiological stereotype) etc. This is a typical 
stereotype, in which the individual stereotypical generalization of knowledge is promoted.

Thus the media text gets new accenting in modern conditions. There is a qualitative transformation of its ontological status, of the media as an intermediary between person and objective reality. All that provides a unified communication, not even contrary to the integrity and adequate perception of social reality. Indeed with the loss of structure-valued information in media, it has lost its relevance as "mass information" because it reflects the processes and events of the objective reality of mass communication and turns into an individualized one [18: 131].

In addition to its informational media text resources, it reveals the connection with the general implication of the mass media and cultural practices: it intrudes into the territory of relevant scientific disciplines, and most of them become a priority providing a universal integration of multiple disciplines, which would also explain the theory of the media as a fundamental base. It is not enough just to "stake out" the borders and domains of cultural studies of media, which is understandable, but it should be more clearly outlined by the studied field of text culture and media interaction [19: 47].

This is one obvious point of view which would refer to the complexity of trans-culturation in the journalistic practice. Trans-culturation means here the global enforcement of professionalization driven by the global media commercializing standards [20:109-110]. When they face the challenge of the journalistic daily job, the communication in different cultures obtains different cultural backgrounds. Based on similar considerations, i.e. on the journalistic practice, G. Baumann, M. Gillespie and A. Sreberny [21] have mentioned it as trans-cultural journalism. In its "translation", "transfer" and "transformation" values it can really inter-culturate beliefs and models of culture, but require at the same time the careful contextual analysis. So the differentiated look at the communicative figurations, in which journalistic practice is integrated, is essential so long as respective production of cultures is articulated.

\section{References}

1. Hennecke, A. (2009). Zum Transfer kulturspezifischer Textbedeutungen. Theoretische und methodische Überlegungen aus einer semiotischen Perspektive. Linguistik Online. 37 (1). p. 35. Available from: http://www.linguistik-online.de/37_09/ hennecke.html (accessed: 15.06.2015).

2. Susmann, V. (2015). Vergleichende Konzeptologie in der Theorie und Praxis der interkulturellen Kommunikation. Interkulturelle Kompetenz: vermitteln, erwerben, anwenden. Ilse Born-Lechleitner, Evelyne Glaser (Hrsg.). Wien; Berlin: LIT Verlag. pp. 31-42.

3. Kirillova, N.B. (2005). Media Culture: from Modern to Post-Modern. Moscow: Akadem. Project. 448 p.

4. Pastukhov, A.G. (2011). Some Ideas for the Integrative Concept of Media: whether the Media Texts have intercultural Differences. Actual Problems of the Language and Culture 
Research. Proceedings of the Scientific Seminar Pastukhov A.G. (ed.). Orel: State Institute of Arts and Culture, "Horizon" Ltd. pp. 9-15.

5. Pastukhov, A.G. (2014). On the Cultural Marking in Media Texts. Formation of Regional Cultural Policy in the Context of Modernization of Education: Proceedings of the International Scientific Conf. Orel: State Institute of Arts and Culture. pp. 212-216.

6. Pastukhov, A.G. (2015). "Different" and "Foreign" in Media Texts: On the Problems of Cross-cultural Interaction. Development of Higher Education in the Culture: Scientific and Educational Experience: Proceedings of the International Scientific Conference (Orel, 26-27 March 2015). N.A. Parshikov et al. (ed.). Orel: State Institute of Culture. pp. 98-103.

7. Millrood, R.P. (2013). Language as a Symbol of Culture. Language and Culture. 2 (22). pp. 43-60.

8. Heringer, H.-J. (2010). Interkulturelle Kommunikation. Grundlagen und Konzepte. Tübingen-Basel: Francke Verlag. 240 p.

9. Perrin, D. (2006). Medienlinguistik. Konstanz: UVK Verlagsgesellschaft GmbH. 248 p.

10. Grishaeva, L.I., Pastukhov A.G., and Chernyshova, T.V. (Eds.). (2010). Media text: strategy - function - style. Orel: State Institute of Arts and Culture, "Horizon" Ltd. 226 p.

11. Grishaeva, L.I. (2014). Paradoxes of Media Linguistics. Voronezh: Science-Unipress. $295 \mathrm{p}$.

12. Boles, D. (2015). Media Literacy. A Glossary of Terms. In: Language of Media Literacy. Available from: http://medialit.org/reading-room/language-media-literacy-glossary-terms (accessed: 17.07.2015).

13. Anisimova, E.E. (2003). Text Linguistics and Intercultural Communication. Moscow: Academy. 128 p.

14. Habscheid, S. (2009). Text und Diskurs. Paderborn: Wilhelm Fink. 122 p.

15. Kallmeyer, W. (Hrsg.). (1986). Kommunikationstypologie. Handlungsmuster, Textsorten, Situationstypen. Jahrbuch 1985 des Instituts für deutsche Sprache. Düsseldorf: Schwann.

16. Adamzik, K. (2008). Textsorten und ihre Beschreibung. In.: Janich, Nina: Textlinguistik. 15 Einführungen. Tübingen: Narr. pp. 145-175.

17. Luckmann, T. (1986). Grundformen der gesellschaftlichen Vermittlung von Wissen: Kommunikative Gattungen. In: F. Neidhardt u.a. (Hrsg.): Kultur und Gesellschaft. Sonderheft 27 der Kölner Zeitschrift für Soziologie und Sozialpsychologie. Opladen: Westdeutscher Verlag. pp. 191-211.

18. Novikova, T.E. (2012). Transformation of Social Institution "Mass Information" in the "Media": from Reflection of objective Reality to Creation of Images of Subjective Reality. Journal of the Nizhny Novgorod Lobachevsky University. Social Sciences Series. 2 (26). pp. 130-134.

19. Pastukhov, A.G. (2015). Publicistic - Journalistic - Medial: to the Formation of a new Stylistic Paradigm. Media and Mass Communication: Experience, Problems and Prospects. Papers of the II International Scientific Colloquium at the Belgorod State University (Oct 1-2, 2014). E.A. Kozhemyakin, A.V. Polonsky (eds.). Belgorod. pp. 45-60.

20. Hepp, A. (2014). Transkulturelle Kommunikation. Konstanz; München: UVK Verlagsgesellschaft GmbH. 293 p.

21. Bauman, N.G., Gillespie, M., and Sreberny, A. (2011). Transcultural Journalism and the Politics of Translation: Interrogating the BBC World Service. Journalism. 12 (2). pp. 135142.

Resived 02.09.2016.

\section{Information about the author}

Pastukhov Alexander - Ph.D., Associate Professor, Head of the Department of Foreign Languages, Orel State Institute of Culture (Orel, Russian Federation). E-mail: alexander.pastukhov@yandex.ru 